\title{
Isidora Aguirre y la renovación del teatro de tema histórico en Chile
}

\section{Osvaldo Obregón}

El teatro de tema histórico en Hispanoamérica ocupa un lugar importante, desde México hasta Chile y Argentina, sobre todo a partir del nacimiento de las diferentes repúblicas a comienzos del siglo XIX. Es una manera, sin duda, de reconstruir el pasado y de establecer analogías con el presente histórico desde el cual se sitúan las sucesivas generaciones de autores. En el valioso legado dramatúrgico que dejó Isidora Aguirre (1919-2011) se puede hablar de un ciclo de obras que se inspira explícitamente en el pasado histórico de América y de Chile, compuesto según el orden cronológico de su creación por los siguientes textos: Lautaro (1982), Diálogos de fin de siglo (1989), Los libertadores Bolivar y Miranda (1993), Manuel Rodríguez (1999) y El adelantado don Diego de Almagro (2003).

De este ciclo histórico en torno a grandes figuras del descubrimiento y conquista de América (Diego de Almagro, Pedro de Valdivia, Lautaro), así como de la lucha por la independencia frente a España (Miranda, Bolívar, San Martín, O’Higgins, Manuel Rodríguez), y el período republicano en Chile (el Presidente Balmaceda y su trágica muerte), sólo haremos referencia a las obras vinculadas a la historia de Chile, razón por la cual dejamos de lado el texto titulado Los libertadores Bolivar y Miranda.

Con el fin de ceñirnos a la cronología histórica y hacer más clara la reconstrucción dramatúrgica elaborada por I. Aguirre, centraremos nuestro enfoque en El adelantado don Diego de Almagro, la última del ciclo, publicada en 2003, al parecer aún no estrenada. Sólo se hizo una lectura dramatizada en el marco del Festival Internacional de Teatro Clásico de Almagro 2006, bajo la dirección de Emilio Hernández. Además, por tratarse de una de sus últimas obras, ha sido hasta ahora menos estudiada que las anteriores. 


\section{Principales elementos del diseño dramatúrgico}

A) Protagonismo y antagonismo de figuras históricas. Se podrá advertir de partida que, con excepción de Diálogos de fin de siglo — en que la figura histórica del Presidente Balmaceda es puramente alusiva-los títulos restantes ponen de relieve personajes de gran envergadura, los cuales tuvieron roles importantes en el momento histórico que les tocó vivir. En relación a la conquista del Imperio incaico, Almagro le disputó a Francisco Pizarro la primacía, como ya veremos. En cuanto al primero, ha pasado a la historia como el "descubridor" de Chile (desde el punto de vista español), lo cual es indiscutible, pero su frustrada exploración hacia el sur del Imperio incaico determinó que pocos años después fuera Pedro de Valdivia quien consolidara la conquista y la colonización del territorio norte del Chile actual, hasta su muerte en manos de los mapuches encabezados por Lautaro, protagonista de la obra de Aguirre ya citada.

La propuesta dramatúrgica que nos ocupa le confiere a Almagro el papel protagónico, lo que al parecer no ha ocurrido en la historia del teatro chileno. Entre sus coetáneos españoles, Pedro de Valdivia ha tenido la primacía por su rol histórico de conquistador y colonizador. La dramaturga reconstruye todo el periplo de Almagro en tierra americana, poniendo más énfasis en las rivalidades entre los jefes españoles - comenzando por Pedrarias/Balboaque en la lucha contra los pueblos amerindios que defendieron sus tierras, sin omitir tampoco las rivalidades entre Huáscar y Atahualpa u otras similares. Sin embargo, el eje central es la relación Almagro/Pizarro, ora socios en la empresa de la conquista, ora enconados adversarios en la lucha por el poder en dos períodos bien marcados cronológicamente: antes y después del viaje de exploración hacia el extremo sur por parte del primero. Hay que subrayar que la primera etapa está marcada por el regreso de Francisco Pizarro desde España junto a sus hermanastros (Hernando, Gonzalo, Juan y Francisco) y un primo (Pedro), viaje que le permitió obtener de la corona española el título de Gobernador y Capitán General y otras importantes concesiones, que van a pesar de manera decisiva para descartar a su rival al regreso de éste desde el sur.

Está muy claro que en la oposición Almagro/Pizarro la dramaturga toma partido por el primero, del cual construye una imagen globalmente positiva, humanizada (que contradice otros testimonios de cronistas), apoyándose en datos verídicos de su biografía: en especial la de hijo bastardo, no reconocido por su padre, que decide lanzarse en la aventura del Nuevo 
Mundo. En pocos años va ganando prestigio guerrero hasta asociarse con Pizarro y el "Cura Luque" en un proyecto para apoderarse de las fabulosas riquezas del Imperio incaico y las de más al sur, según diversos testimonios orales, que están en el origen de su viaje a Chile, el cual resultó a la postre un desastre humano y financiero. Después de su increíble ascensión, debe afrontar el fracaso de su expedición, seguido de su enfrentamiento armado con los Pizarro, su derrota en la batalla de Las Salinas, su encarcelamiento y condena a muerte (1538). Termina la obra con la lectura de su testamento, a cargo del Padre Bobadilla.

B) División del texto. Previamente, es de notar la presencia de dos paratextos: el primero es una estrofa breve (cuatro versos) de autor anónimo: "Estos infelices capitanes / Que no fueron capaces / De vivir sin su muerte / E las ajenas", referencia de alcance trágico a los capitanes españoles de la Conquista, texto integrado también al último parlamento, a cargo del Padre Bobadilla, oficiante de las exequias de Almagro, formulados con mayúscula los tres últimos versos. El segundo paratexto, compuesto de dos párrafos en prosa, es una cita del cronista Gonzalo Fernández de Oviedo referida a Diego de Almagro en términos encomiásticos, la cual prefigura un tratamiento positivo del personaje histórico.

El texto propiamente dramatúrgico está formalmente dividido en dos partes, sin anuncio de intermedio, lo que significa que el encargado eventual de la puesta en escena tiene la opción de la continuidad o de la interrupción del espectáculo. Cada parte está constituida de fragmentos. En la primera son identificados con subtítulos de dos categorías entremezcladas: los denominados "entremeses de los indios" (cuatro), caracterizados por su brevedad textual, y fragmentos más largos: "Luz de trópico", "Cambio a luz de trópico", "Reflejos de agua al fondo" y "Espectáculo: música y coreografía 'La muerte de Atahualpa"', que da fin a la primera parte. La segunda parte es menos fragmentada. Comienza con una secuencia sin título, seguida de otras identificadas claramente: "A modo de entremés", "La batalla de Las Salinas" y "Escena final en contrapunto". Representa una división poco frecuente y que responde a una propuesta que pretende renovar el género histórico, como veremos después. La autora deja en evidencia una revisión de ciertas fuentes históricas consultadas e incluso la inserción de tres citas es objeto de las notas correspondientes. Según el orden: "De una elegía quichua" (1); "Tomado de las crónicas de Garcilazo de la Vega" (2) y "Trozos tomados del testamento real de Almagro" (3). Este último intertexto sirve de base para la escena final. 
C) Estructuración del tiempo y del espacio. A diferencia de la segunda parte, la primera tiene un subtítulo que establece claramente el marco espacio-temporal en que se desarrolla: "Villa de Urcos, cerca del Cuzco, Perú, 1537", es decir, de regreso de su expedición hacia el sur y un año antes de su muerte. A partir de la fecha citada y de manera retrospectiva, se reconstruyen sintéticamente los episodios principales de la vida de Almagro, mediante sus recuerdos insertos en sus diálogos con Malgárida, su concubina, en que se mezclan sus comentarios sobre su fallida expedición, los años de su infancia y juventud en España, su llegada a América, su relación con Pizarro y otros españoles en busca de fortuna y renombre. En otras secuencias, se recrean las situaciones más relevantes de su aventura americana, en que dominan sus cambiantes relaciones con Pizarro y sus aventuras guerreras, en alternancia con los breves entremeses, que muestran la visión indígena de la conquista, en que el perfil de los españoles es percibido como sanguinario y rapaz. La $1^{\text {a }}$ parte termina con una secuencia iniciada por el encuentro con Atahualpa en Cajamarca, la entrada triunfante al Cuzco, la decapitación del emperador inca y concluye con un enfrentamiento verbal entre Pizarro y Almagro, en el cual ambos difieren en cuanto al modo de llevar la conquista y en que este último se muestra particularmente autocrítico, acerca de la manera de tratar a los indígenas. Triunfadores los dos, se acerca la hora de la lucha por el poder, que se verá aplazada por su expedición al actual territorio chileno, donde se creía que existía otro imperio tan rico como el incaico.

La $2^{\mathrm{a}}$ parte se concentra temporalmente en el último año de la vida de Almagro (1537-1538). Ahora prima el presente con todas las tensiones que engendra la rivalidad descarnada entre los partidarios de Almagro y los de Pizarro, con una diferencia muy importante: Almagro se enfrenta ahora a Hernando Pizarro, hermano del anterior, el cual ha quedado como Gobernador del Cuzco, gobernación a la cual pretende también Almagro. La propuesta de Aguirre imagina un encuentro previo al choque guerrero entre ambos, que no resuelve la situación, en tanto Francisco Pizarro se ocupa de la lejana ciudad de Lima recién fundada. Almagro logra imponerse sobre Hernando y es nombrado Gobernador del Cuzco, sin embargo perdona la vida a éste. Gana la batalla de Abancay, pero pierde la definitiva: Las Salinas, siendo poco después hecho prisionero por Hernando y condenado a muerte. En esta segunda parte, se desvanece la figura de Francisco Pizarro. El antagonismo Diego versus Francisco se transforma en el de Diego versus Hernando. 
D) Diálogo y narración. Aunque predomina la forma dialogada, en varios momentos se intercalan textos narrativos destinados a informar al espectador de los sucesos inherentes a la vida de Almagro antes de partir a América o de algunos hechos de la conquista en los cuales le tocó participar. En ambos casos, es el propio Almagro el que hace confidencias acerca de su bastardía y de su madre ausente o el que esboza una crónica de su embarque en Sanlúcar de Barrameda y de sus expectativas futuras como colono. Otras veces son los "Soldados" los que narran en forma coral algunos acontecimientos o un "Escribano" que narra la batalla de Las Salinas. En los "entremeses" se utiliza el mismo procedimiento narrativo a cargo de los "Informantes", los cuales ilustran en breves líneas la perspectiva indígena para comentar la guerra de conquista, excepto en la secuencia sobre "La muerte de Atahualpa", que da fin a la primera parte, en que los autóctonos tienen un rol más importante.

E) Fusión de géneros artísticos. La autora fue siempre fiel al soporte textual, pero el elemento musical ha sido importante en varias propuestas anteriores y esencial en La pérgola de las flores. En su ciclo histórico, incluyendo El adelantado don Diego de Almagro, utiliza también otros géneros, como se verá a continuación. Estrechamente aliada al texto, la música es un elemento recurrente, ya sea para reforzar ciertas escenas, ya sea como elemento de "separación" entre ellas. En este último caso se trata de música grabada, en cambio en el primer caso se maneja la música en vivo, muy presente en los "entremeses". En varios momentos se mezcla música, percusión, danza y máscara ritual. Casi al final de la primera parte, en una secuencia metateatral, se representa un espectáculo titulado "La muerte de Atahualpa", con música, coreografía, mímica y "muñecos" (marionetas), con un texto en que se mezclan narración y diálogo. En otros momentos se vale de la proyección de grabados antiguos para ilustrar la gesta de la conquista o de combinaciones de música incidental, sonidos e iluminación, como es el caso del inicio de la secuencia titulada "La batalla de Las Salinas", que significó la derrota de Almagro.

Si aplicáramos la misma pauta precedente a las otras obras del ciclo histórico, encontraríamos varios rasgos comunes. El deber de síntesis nos obliga a elegir sólo este último, al que le atribuimos una importancia mayor en la estructura dramatúrgica.

Los fundamentos temáticos de Lautaro - el choque de civilizaciones, la compleja relación entre Valdivia y Lautaro, la revaloración de la etnia mapuche - se prestaban a la construcción de una dramaturgia de variados 
registros: ritos chamanísticos que integran la danza, el uso de máscaras ceremoniales y música mapuche; danzas guerreras; cantos y bailes andaluces; integración de composiciones musicales del famoso grupo chileno Los Jaivas; música incidental para ambientar algunos momentos; música de separación, también grabada, y utilización de la forma coral: todos ellos se fusionan y potencian la dramaturgia textual.

En Manuel Rodríguez, la música y el canto abren y cierran algunas escenas, generadas por el Coro Popular. Otras veces el canto se acompaña de baile, creando un clima festivo con sabor popular en espacios abiertos, calles o plazas, contrapartida de la dimensión trágica, como destino último del protagonista. A ello se agrega en algunas secuencias el uso de proyecciones, como en la escena final, que culmina con la "Canción de Manuel" y en que se proyecta al Guerrillero "montado en primer plano, lomas suaves. Y alejándose, se pierde entre los cerros" (Aguirre, Antología 132), imagen emblemática que remite a la teleserie que protagoniza el Zorro, personaje que podría perfectamente haberse inspirado en Manuel Rodríguez y su leyenda.

En Diálogos de fin de siglo a fusión de géneros artísticos ocupa un lugar más modesto, comparada con las obras precedentes. Sin embargo, la música y el canto refuerzan el desarrollo de varias secuencias. El joven Felipe, impregnado del romanticismo de finales del s. XIX, está asociado a su sonata preferida, gusto musical que comparte con Rosario, su madrastra. Ambos disienten de Alberto, respectivamente padre y esposo, debido a su posición anti-balmacedista. La sonata es un verdadero leit-motif de la propuesta dramatúrgica, desde el comienzo hasta el trágico final de la muerte accidental de Felipe. Otras escenas están reforzadas por la música callejera del Organillero. Uno de los cuadros transcurre en un Palco del Teatro Municipal de Santiago, donde se representa la ópera El Trovador (1853) de Giuseppe Verdi, pero hay también algunos cantos callejeros y montajes de sonidos.

\section{Conclusiones}

En El adelantado don Diego de Almagro, última obra del ciclo histórico, Isidora Aguirre confirma una concepción dramatúrgica que rompe con los moldes habituales en su país: 1) preferencia por la división en dos partes sin intermedio, cada una de las cuales se subdivide en varias secuencias; en lugar de actos utiliza unidades más breves, como cuadros, jornadas, entremeses, interludios, lo que le permite rápidos cambios temporales y espaciales; 2) la cronología de la acción dramática, que es, a menudo, alterada en la $1^{\text {a }}$ parte, ya sea con recuentos a cargo de Almagro, ya sea con escenas breves que 
remiten al pasado, en oposición a la $2^{\mathrm{a}}$, que se concentra en el último año de la vida del protagonista; 3 ) predominio de la forma dialogada, con mezcla de narración, destinada a informar sobre ciertos hechos, como la batalla de Las Salinas u otros y 4) la pluralidad de lenguajes escénicos, que es uno de los rasgos más relevantes: ritos, música, danza, marionetas, sonidos, iluminación y proyecciones de grabados antiguos refuerzan el poder del texto, como lo ilustra la secuencia titulada "La muerte de Atahualpa".

Importa señalar también que en el ciclo histórico, la dramaturga se vale de las analogías entre el pasado y el presente, las cuales son mejor explotadas en las obras anteriores a El adelantado don Diego de Almagro, sobre todo en Lautaro y Diálogos de fin de siglo, en que las analogías recaen sobre el período de la dictadura de Pinochet. En todas ellas, la dramaturga elude un enfoque realista, introduciendo escenas en que se mezcla "lo real y lo irreal" e integrando con fluidez los postulados más relevantes del teatro contemporáneo occidental, sustentados por Artaud (la importancia de lo ritual), Brecht (su postura del teatro épico) y el teatro-documento de Peter Weiss, entre los más importantes. Esto le ha permitido a Isidora Aguirre recrear, con gran imaginación, períodos claves y figuras paradigmáticas de la historia de Chile, confrontándolos con los del tiempo en que le tocó vivir, renovando de esta manera el teatro de tema histórico en su país.

\section{Université de Franche-Comté, Besançon, Francia}

\section{Obras citadas}

Aguirre, Isidora. El adelantado don Diego de Almagro. Santiago: Editorial Clan, 2003. . Antología esencial. 50 años de dramaturgia (14 obras, entre ellas las cuatro de referencia). Santiago: Ediciones Frontera Sur, 2007. (Prólogo de Alicia del Campo, p. 7-25) . Diálogos de fin de siglo. Santiago: Editorial Torsegel, 1988. . Lautaro (epopeya del pueblo mapuche). Santiago: Editorial Nascimento, 1982. . Manuel Rodríguez. Santiago: Editorial Clan, 1999.

Fernández, Teodosio. "Isidora Aguirre y el nuevo teatro histórico". Márquez Montes 41-52.

González, Patricia E. "Isidora Aguirre y la reconstrucción de la historia en Lautaro". Latin American Theatre Review 19.1 (1985): 13-18.

Gotschlich, Guillermo. "Hablar por los que no tienen voz". Teatro chileno contemporáneo. Madrid: Ministerio de Cultura / Fondo de Cultura Económica, 1992. 1101-06. 
Hurtado, María de la Luz. "Isidora Aguirre al trasluz de la historia". Resistencia y poder: Teatro en Chile. Eds. Heidrun Adler y George Woodyard. Madrid: Vervuert /Iberoamericana, 2000. 57-74.

Husson, Jean-Phillipe. La Mort d'Ataw Walpa ou La fin de l'Empire des Incas. Édition critique trilingue (quechua - espagnol - français). Genève: Editions Patiño, 2001.

Márquez Montes, Carmen, coord. Isidora Aguirre. Entre la historia y el compromiso. Colección Escritores del Cono Sur 3. Sevilla: Secretariado de Publicaciones de la Universidad de Sevilla, 2008.

Obregón, Osvaldo. "Fulgor, muerte y legado de Lautaro, emblema del pueblo mapuche". Márquez Montes 27-40.

Rodríguez P, Osvaldo. "Diálogos de fin de siglo, de Isidora Aguirre". Márquez Montes 53-62. 